\title{
SENAM DISMENOR DALAM MENURUNKAN SKALA NYERI HAID PADA REMAJA
}

\author{
Dismenor Gymnastics in Reducing Menstrual Pain in Adolescents \\ Rosi Kurnia Sugiharti \\ Universitas Harapan Bangsa Purwokerto \\ (rosikurnia23@gmail.com)
}

\begin{abstract}
ABSTRAK
Latar Belakang : Gangguan fisik yang sangat menonjol pada wanita haid adalah Nyeri Haid. Nyeri haid dapat ditangani dengan terapi secara farmakologis atau non farmakologis. Salah satu terapi non farmakologis yang dapat menurunkan nyeri haid primer pada remaja adalah senam dismenor.

Tujuan :Penelitian ini bertujuan untuk mengetahui pengaruh senam dismenor terhadap penurunan skala nyeri haid pada remaja.

Metode : Model penelitian yang digunakan adalah quasi eksperimen. Rancangan penelitian ini adalah one group pre and post tes design yaitu dengan menggunakan satu kelompok responden di mana kelompok tersebut diberikan perlakuan Sampel dengan menggunakan purposive sampling. Subyek penelitian ini remaja yang mengalami nyerihaid primer berjumlah 20 orang. Analisa data dalam penelitian ini menggunakan Uji $T$ Test Berpasangan dengan terlebih dahulu dilakukan uji normalitas data dengan Shapiro Wilk.

Hasil : Berdasarkan pada hasil penelitian yang telah didapatkan rata-rata usia responden adalah 19,7 tahun dengan usia minimum 18 tahun dan maximum 21 tahun. Sebagian besar responden mengalami penurunan skala nyeri pre yaitu nyeri sedang dengan prosentase $65 \%$, sedangkan pada pengukuran post sebagian responden mengalami penurunan nyeri haid menjadi tidak nyeri dengan prosentase $40 \%$, selain itu juga ada peningkatan jumlah responden yang tidak mengalami nyeri haid menjadi $40 \%$ dari $0 \%$. Berdasarkan hasil uji statistik Uji T berpasangan didapatkan hasil bahwa nilai $\mathrm{P}$ value adalah 0,0001 yang berati $<\alpha$ 0,05 yang menyimpulkan bahwa Ha diterima dan Ho ditolak.
\end{abstract}

Simpulan: Ada pengaruh senam dismenor terhadap penurunan nyeri haid primer pada remaja.

Kata kunci: senam dismenor,nyeri haid, remaja 


\begin{abstract}
Background: Physical disorders that are very prominent in menstruating women are menstrual pain. Menstrual pain can be treated with pharmacological or nonpharmacological therapy. One of the non-pharmacological therapies that can reduce primary menstrual pain in adolescents is dysmenor exercise.

Purpose: This study aims to determine the effect of dysmenor exercise on reducing the scale of menstrual pain in adolescents.

Methods: The research model used is a quasi-experimental study. The design of this research is one group pre and post test design, namely by using a group of respondents in which the group is given treatment Samples using purposive sampling. The subjects of this study were 20 adolescents who experienced primary pain. Analysis of the data in this study using the Paired T Test with the normality test of the data with Shapiro Wilk first.

Results: Based on the results of the study, the average age of the respondents was 19.7 years with a minimum age of 18 years and a maximum of 21 years. Most of the respondents experienced a decrease in the pre pain scale, namely moderate pain with a percentage of $65 \%$, while in the post measurement some respondents experienced a decrease in menstrual pain to become painless by a percentage of $40 \%$, besides that there was also an increase in the number of respondents who did not experience menstrual pain to $40 \%$ from $0 \%$. Based on the results of the paired T test statistical test, it was found that the P value was 0.0001 which means $<\alpha 0.05$ which concluded that Ha was accepted and Ho was rejected.
\end{abstract}

Conclusion: There is an effect of dysmenor exercise on reducing primary menstrual pain in adolescents.

Key words: dysmenor exercise, menstrual pain, adolescents

\title{
PENDAHULUAN
}

Pubertas merupakan masa transisi antara masa anak dan dewasa dimana terjadi pacu tumbuh (growth spurt), dan relatif belum mencapai tahap kematangan mental dan sosial sehingga mereka harus menghadapi tekanan emosi dan sosial yang saling bertentangan. Menurut WHO, remaja adalah bila anak telah mencapai umur 10 - 18 tahun (Andira,2012). Perubahan perkembangan biologis, ditandai dengan keremajaan secara biologi yaitu di mulainya haid (menstruasi). Gangguan fisik yang sangat menonjol pada wanita haid adalah Nyeri Haid. Penyebab dismenore ini berbeda- beda, dapat dikarenakan penyakit (radang panggul), endometriosis, tumor atau kelainan uterus, stres atau cemas yang berlebihan, bisa juga dikarenakan ketidakseimbangan hormonal dan tidak terdapat adanya hubungan dengan organ reproduksi. Faktor-faktor yang dapat menyebabkan dismenore primer yaitu faktor kejiwaan yang secara emosional tidak stabil yang terjadi pada saat gadis remaja, apabila tidak mendapatkan penerangan yang baik tentang proses menstruasi,dan berkaitan juga dengan peningkatan hormon yaitu hormon prostaglandin yang dapat meningkatkan 
kontraksi miometrium dan dapat mempersempit pembuluh darah, sehingga dapat mengakibatkan kontraksi otot-otot Rahim (Dewi, 2012).

Dismenore dapat diatasi dengan berbagai cara yaitu dengan cara farmakologi dan non farmakologi. Secara non farmakologi dapat dilakukan dengan kompres hangat, mandi air hangat, yoga, distraksi, pijatan, tidur/istirahat dan olahraga atau senam. Olahraga atau senam dilakukan ketika pagi atau sore hari, sebaiknya dilakukan 3-5 kali seminggu selama 30 menit (Martchelina I, 2011).

Senam dismenore adalah senam yang membantu peregangan seputar otot perut, panggul dan pinggang. Selain itu, senam dismenore dapat memberikan perasaan nyaman yang berangsur-angsur dan dapat mengurangi nyeri jika dilakukan secara teratur. Adapun tujuan dilakukan senam dismenore yaitu: membantu mengurangi rasa nyeri pada remaja yang sedang mengalami dismenore dan mencegah dismenore, alternatif terapi dalam mengatasi dismenore dan intervensi yang nantinya dapat diterapkan pada pelayanan asuhan keperawatan bagi yang mengalami masalah dismenore yang sering dialami remaja (Dito, 2011). Berdasarkan studi pendahuluan yang diperoleh remaja belum mengetahui manfaat dari senam dismenor dalam menurunkan nyeri haid primer. Dari permasalahan diatas maka peneliti tertarik untuk melakukan penelitian tentang pengaruh senam dismenor terhadap penurunan nyeri haid primer pada remaja.

\section{METODE PENELITIAN}

Model penelitian yang digunakan adalah quasi eksperimen karena syaratsyarat dalam penelitian eksperimen tidak cukup memadai yaitu tidak melakukan dilakukan kontrol terhadap variabel-variabel yang berpengaruh terhadap eksperimen. Rancangan penelitian ini adalah one group pre and post tes design yaitu dengan menggunakan satu kelompok responden di mana kelompok tersebut diberikan perlakuan (Nursalam,2013). Sampel dengan menggunakan purposive sampling. Subyek penelitian ini remaja yang mengalami nyerihaid primer berjumlah 20 orang. Analisa data dalam penelitian ini menggunakan Uji T Test Berpasangan dengan terlebih dahulu dilakukan uji normalitas data dengan Shapiro Wilk.

\section{HASIL DAN PEMBAHASAN}

\section{Hasil}

Setelah dilakukan penelitian dengan mengadakan wawancara dan pengisian data ke dalam kuesioner kepada para mahasiswa prodi kebidanan sejumlah 20 orang yang memiliki rentang usia 18 sampai dengan 21 tahun mengenai pengaruh senam dismenor terhadap penurunan nyeri haid pada remaja, diperoleh data sebagai berikut: 
Tabel 1. Karakteristik Reponden Berdasarkan Usia

\begin{tabular}{llllll}
\hline & Mean & Median & Standar Deviasi & Minimum & maksimum \\
\hline Usia & 19,70 & 20,00 & 0,801 & 18 & 21
\end{tabular}

Berdasarkan tabel 1 diketahui bahwa rata-rata usia responden adalah 19 tahun 7 bulan, umur minimal adalah 18 tahun dan umur maksimal responden adalah 21 tahun.

Tabel 2. Nyeri haid sebelum intervensi

\begin{tabular}{lcl}
\hline Nyeri haid & Frekuensi & Prosentase $(\%)$ \\
\hline Tidak Nyeri & 0 & 0 \\
Nyeri ringan & 5 & 25 \\
Nyeri Sedang & 13 & 65 \\
Nyeri Berat & 2 & 10 \\
Nyeri tak tertahankan & 0 & 0 \\
\hline Total & 20 & 100 \\
\hline
\end{tabular}

Berdasarkan tabel 2 dapat diketahui bahwa nyeri haid yang dialami responden sebelum intervensi sebagian besar berada pada kategori nyeri sedang yaitu sebanyak 13 responden $(65 \%)$.

Tabel 3. Nyeri haid setelah intervensi

\begin{tabular}{lcc}
\hline Nyeri Haid & Frekuensi & Prosentase(\%) \\
\hline Tidak Nyeri & 8 & 40 \\
Nyeri ringan & 5 & 25 \\
Nyeri Sedang & 6 & 30 \\
Nyeri Berat & 1 & 5 \\
Nyeri tak tertahankan & 0 & 0 \\
\hline Total & 20 & 100 \\
\hline
\end{tabular}

Berdasarkan tabel 3 dapat diketahui bahwa nyeri haid pada responden setelah intervensi sebagian besar berada pada kategori tidak nyeri yaitu sebanyak 8 responden (40\%). 
Tabel 4. Nyeri haid Sebelum dan Sesudah intervensi

\begin{tabular}{lllll}
\hline Nyeri & \multicolumn{2}{c}{ Sebelum } & \multicolumn{2}{c}{ Sesudah } \\
\cline { 2 - 5 } Haid & F & $\%$ & F & $\%$ \\
\hline Tidak Nyeri & 0 & 0 & 8 & 40 \\
Nyeri ringan & 5 & 25 & 5 & 25 \\
Nyeri sedang & 13 & 65 & 6 & 30 \\
Nyeri berat & 2 & 10 & 1 & 5 \\
Nyeri tak tertahankan & 0 & 0 & 0 & 0
\end{tabular}

Berdasarkan tabel 4. diketahui bahwa sebelum dilakukan intervensi sebagian reponden mengalami nyeri hadi sedang yaitu sebanyak 13 orang (65\%), kemudian setelah dilakukan intervensi sebagian besar responden sudah tidak mengalami nyeri haid yaitu sebanyak 8 orang (40\%). Hasil penelitian menunjukkan bahwa terjadi peningkatan penurunan nyeri haid dengan kriteria nyeri sedang menjadi tidak nyeri setelah responden melakukan senam dismenor dan diukur kembali skala nyerinya setelah 1 jam senam dismenor.

Tabel 5. Pengaruh Senam Dismenor Terhadap Penurunan Nyeri Haid

\begin{tabular}{llll}
\hline Skala Nyeri & Mean & Standar Deviasi & P Value \\
\hline Pre intervensi & 1,85 & 0,587 & 0,0001 \\
Post Intervensi & 1,00 & 0,973 & \\
\hline
\end{tabular}

Berdasarkan tabel 5 dapat disimpulkan bahwa dari hasil perhitungan dengan menggunakan Uji T berpasangan yaitu dengan membandingkan nyeri haid yang dialami responden sebelum dilakukan intervensi dan setelah dilakukan intervensi menunjukkan ada pengaruh senam dismenor terhadap penurunan nyeri haid primer yang ditunjukkan dengan nilai $\mathrm{P}$ value $=0,0001$ yang berati $<\alpha 0,05$. Hal ini menyebabkan Ha diterima dan Ho ditolak yaitu ada pengaruh senam dismenor terhadap penurunan nyeri haid primer pada remaja.

\section{Pembahasan}

Tabel 1 menunjukkan hasil bahwa rata-rata usia responden adalah 19,7 tahun dengan usia minimum 18 tahun dan maximum 21 tahun. Hal ini sesuai dengan penelitian sebelumnya yaitu penelitian yang dilakukan oleh Ida Nurjanah (2019) yang menyatakan bahwa remaja yang mengalami dismenor adalah remaja yang berusia 18-21 tahun. Penelitian lainnya oleh Lina Susanti (2017) menunjukan bahwa rata-rata usia responden yang mengalami dismenore adalah 18-19 tahun. Berdasarkan penelitian sebelumnya, distribusi frekuensi umur responden pada mahasiswi sebagian besar responden yang mengalami dismenore yaitu pada masa remaja akhir karena keadaan fisik dan psikis seperti stres dan peningkatan hormon prostaglandin dan progesteron. 
Berdasarkan tabel 4 dapat diketahui bahwa sebagian besar responden mengalami penurunan skala nyeri pre yaitu nyeri sedang dengan prosentase $65 \%$, sedangkan pada pengukuran post sebagian responden mengalami penurunan nyeri haid menjadi tidak nyeri dengan prosentase $40 \%$, selain itu juga ada peningkatan jumlah responden yang tidak mengalami nyeri haid menjadi $40 \%$ dari $0 \%$. Hasil penelitian sejalan dengan penelitian Ulfah (2015) yang menunjukkan bahwa ada perbedaan skala nyeri dismenor setelah dilakukan intervensi senam dismenor. Senam dapat meningkatan jumlah dan ukuran pembuluh - pembuluh darah yang menyalurkan darah keseluruh tubuh. Jadi olahraga penting untuk remaja putri yang mengalami dismenore karena latiahan yang sedang dan teratur akan meningkatkan pelepasan endorfin beta (penghilang nyeri alami) kedalam aliran darah, sehingga dapat mengurangi nyeri haid atau dismenore (Ulfah, 2015).

Dalam penelitian Winy (2014) dengan judul efektifitas teknik relaksasi terhadap upaya penanganan dismenore pada mahasiswi STiKes PKU Muhammadiyah Surakarta menyatakan bahwa terdapat perbedaan skala nyeri yang signifikan antara sebelum dan sesudah dilakukan teknik relaksasi progresif dimana terdapat penurunan skala nyeri dari nyeri sedang menjadi nyeri ringan. Penurunan skala nyeri ini terjadi karena terapi dengan teknik relaksasi memberikan individu kontrol diri ketika terjadi rasa tidak nyaman atau nyeri, stress fisik dan emosi pada nyeri.Kegiatan ini menciptakan sensasi melepaskan ketidaknyamanan dan stress.Secara bertahap, klien dapat merelaksasikan otot tanpa harus terlebih dahulu menegangkan otot-otot tersebut.Saat klien mencapai relaksasi penuh maka persepsi nyeri berkurang dan rasa cemas terhadap pengalaman nyeri menjadi minimal.

Berdasarkan tabel 5 dapat diketahu bahwa dari hasil uji statistik Uji $T$ berpasangan didapatkan hasil bahwa nilai $\mathrm{P}$ value adalah 0,0001 yang berati $<\alpha$ 0,05 yang menyimpulkan bahwa Ha diterima dan Ho ditolak. Hal ini menunjukan bahwa ada pengaruh senam dismenor terhadap penurunan nyeri haid primer pada remaja. Hasil penelitian ini juga sesuai dengan penelitian Munawar, Nurjannah \& Fiki Nurviana (2012) dengan judul the effect of aerobics on reducing the pain of dysmenorrhea yang menyatakan bahwa terdapat perbedaan nyeri dengan menggunakan skala pengukuran NRS (numeric rating scale) dengan $p$-value $(0,00)$.

Saat ini patofisiologi terjadinya dismenorea primer memang masih belum jelas karena banyaknya faktor yang mempengaruhi terjadinya dismenorea primer pada remaja putri. Hasil penelitian sejalan dengan teori yang mengatakan bahwa dismeorhea primer yang dipercaya kebenarannya yaitu teori prostaglandin dan leukotriene. Penurunan hormon progesteron dan estrogen pascaovulasi nonfertilisasi menyebabkan menstruasi yang mengakibatkan aktivasi siklus prostaglandin dan leukotrien dalam uterus . Respons inflamasi akibat siklus prostaglandin di dalam uterus akan berakibat pada hipertonus dan vasokonstriksi pada miometrium. Akhirnya timbul iskemia dan nyeri pada dismenorea primer. Substansi spesifik yang menyebabkan hal ini adalah prostaglandin (PG) F2-alfa. 
Prostaglandin F2 alfa adalah salah satu perangsang kuat kontraksi otot polos myometrium dan kontriksi pembuluh darah uterus (Eny, 2011).

Hasil penelitian ini juga sesuai dengan hasil penelitian yang dilakukan oleh Marlinda (2013) yang melakukan penelitian tentang pengaruh senam dismenor terhadap penurunan dismenor pada remaja putri memperoleh hasil bahwa ada pengaruh senam dismenore terhadap dismenore yang dialami oleh remaja. Untuk mengatasi ketidaknyamanan akibat nyeri haid, ada beberapa cara yang dapat dilakukan untuk mengatasi hal tersebut. Salah satunya adalah senam dismenore.Tujuan dari senam dismenore adalah meningkatkan ketegangan otot-otot dan pembuluh darah yang jarang sekali bisa menurunkan tegangan darah tinggi Dengan pemberian kompres air dingin Peningkatan volume darah yang mengalir keseluruh tubuh, termasuk organ reproduksi. Dengan olahraga rutin atau senam terjadi peningkatan volum darah yang mengalir keseluruh tubuh, termasuk organ reproduksi sehingga memperlancar pasokan oksigen ke pembuluh darah yang mengalami vasokontraksi, sehingga nyeri haid dapat berkurang.

Senam dismenore merupakan aktivitas fisik yang dapat digunakan untuk mengurangi nyeri. Saat melakukan senam, tubuh akan menghasilkan endorphin. Hormon endorphin yang semakin tinggi akan menurunkan atau meringankan nyeri yang dirasakan seseorang sehingga seseorang menjadi lebih nyaman, gembira, dan melancarkan pengiriman oksigen ke otot (Sugani \& Priandarini, 2010). Senam dismenore dapat menurunkan intensitas nyeri melalui mekanisme, yaitu dengan merelaksasikan otot-otot yang mengalami spasme yang disebabkan oleh peningkatan prostaglandin sehingga terjadi vasodilatasi pembuluh darah dan akan meningkatkan aliran darah ke daerah yang mengalami spasme dan iskemik. Selain itu, saat melakukan suatu exercise dalm hal ini adalah senam dismenore, tubuh akan mengeluarkan opoid endogen yaitu endorphin dan enkefalin yang dihasilkan di otak dan sumsum tulang belakang. Zat-zat tersebut memiliki sifat mirip morfin dengan efek analgetik yang membentuk suatu sistem penekan nyeri (Haruyama,2011).

\section{SIMPULAN DAN SARAN}

\section{Simpulan}

Rata-rata usia responden adalah 19,7 tahun dengan usia minimum 18 tahun dan maximum 21 tahun. responden mengalami penurunan skala nyeri pre yaitu nyeri sedang dengan prosentase $65 \%$, sedangkan pada pengukuran post sebagian responden mengalami penurunan nyeri haid menjadi tidak nyeri dengan prosentase $40 \%$, selain itu juga ada peningkatan jumlah responden yang tidak mengalami nyeri haid menjadi $40 \%$ dari $0 \%$. hasil uji statistik $U j i T$ berpasangan didapatkan hasil bahwa nilai $\mathrm{P}$ value adalah 0,0001 yang berati $<\alpha$ 0,05 yang menyimpulkan bahwa Ha diterima dan Ho ditolak. Hal ini menunjukan bahwa ada pengaruh senam dismenor terhadap penurunan nyeri haid primer pada remaja. 


\section{Saran}

Bagi remaja diharapkan teratur dalam melakukan senam dismenor sehingga saat mengalami menstruasi tidak mengalami nyeri haid. Bagi tenaga kesehatan diharapkan dapat memberikan informasi dan pelatihan senam dismenor bagi remaja yang mengalami nyeri haid.

\section{DAFTAR PUSTAKA}

Andira, Dita. 2012.Seluk Beluk Kesehatan Reproduksi Wanita: Jogjakarta:A Plus Books.

Anurogo, Dito. 2011.Cara Jitu Mengatasi Nyeri Haid. Yogyakarta: ANDI

Dewi SN. 2012. Biologi Reproduksi. Yogyakarta: Pustaka Rihama

Haruyama, S. 2011. The miracle of endhorphin: Sehat mudah dan praktis dengan hormon kebahagiaan. Jakarta: Qonita PT. Mizan Pustaka

Ida Nurjanah. 2019. Pengaruh Senam Dismenore Terhadap Penurunan Nyeri Menstruasi Pada Mahasiswi Asrama Stikes Muhammadiyah Palembang. Syifa Medika Jurnal Kesehatan dan Kedokteran Vol 10, No 1 (2019)

Kusmiran, Eny. 2011. Kesehatan Reproduksi Remaja dan Wanita. Jakarta: Salemba Medika

Lina Susanti.2017. Pengaruh Senam Dismenore Terhadap Penurunan Dismenor Mahasiswi TK II Keperawatan. Madiun : STIKES Bhakti Husada Mulia http://repository.stikes-bhm.ac.id/id/eprint/211

Marlinda R,Rosalina, Purwaningsih P. Pengaruh Senam Dismenore Terhadap Penurunan Dismenore Pada Remaja Putri Di Desa Sidoharjo Kecamatan $\begin{array}{llll}\text { Pati. J } & \text { Keperawatan }\end{array}$ 1(2).http://jurnal.unimus.ac.id/index.php/JKMat/article/view/998

Martchelina I. 2011. Pengaruh Senam Dismenore terhadap Penurunan Tingkat Nyeri Saat Menstruasi pada Remaja Putri usia 12-17 tahun SMP 131 di Cipedak Kecamatan Jagakarsa. Jakarta: Universitas Pembangunan Nasional Veteran. http://www.library.upnvj.ac.id

Munawar., Nurjannah., Nurviana, F. 2012.The effect of aerobics on reducing the pain of dysmenorrhea. http://download.portalgaruda.org/article

Nursalam. 2013. Metodologi Penelitian Ilmu Keperawatan Pendekatan Praktis Ed.3. Jakarta : Salemba Medika

Sugani dan Priandarini. 2010. Cara cerdas untuk sehat : Rahasia hidup sehat tanpa dokter. Jakarta: Transmedia

Ulfa TF. 2015. Pengaruh Senam Dysmenorhea terhadap Skala Nyeri Dysmenorhea pada Remaja Putri di SMP Ali Maksum Yogyakarta Tahun 2015. STIKES 'Aisyiyah $\quad$ Yogyakarta; 2015. http://opac.unisayogya.ac.id/id/eprint/775

Winy P, Rahma. 2014. Efektifitas teknik relaksasi terhadap upaya penanganan dismenorhea pada mahasiswi StiKes PKU Muhammadiyah Surakarta. http://stikespku.ac.id 